\title{
High Voltage X-Ray Therapy
}

$\mathrm{T}$ HE formal opening of the Mozelle Sassoon High Voltage X-Ray Therapy Department of St. Bartholomew's Hospital, London, took place on December 10. This splendid department owes its existence to the far-seeing generosity of Mrs. Meyer Sassoon, who gave the considerable sum of money required for its erection and equipment. It has been established with the object of promoting the relief and cure of cancer by the application of the most recent developments in physical science.

There are three main limitations to the effectiveness of present-day technique in radiation therapy : the difficulty of the delivery of an adequate dose of radiation to a tumour or site deep in the body, without damage to overlying structures; the difficulty of giving this dose within a reasonably short exposure time; and the narrow margin of safety, due to the small difference in radiosensitivity, between normal and malignant tissues. The first of these can be overcome by means of a sufficiently penetrat ing radiation; the second by the use of high intensities of radiation; while differences in radiosensitivity depend in part upon the wave-length of the radiation employed.

The new installation is designed to give a beam of X-rays of greater penetrative power, of higher intensity, and of shorter mean wave-length, than any so far employed in the treatment of cancer. Furthermore, since the apparatus may be operated at any voltage from 250,000 volts up to $1,000,000$ volts, its range and flexibility will permit the choice of the optimum conditions of treatment which may be found applicable in different cases.

Side by side with this work will proceed the investigation of the physical, chemical, and bio-



FIG. 1. Treatment room.

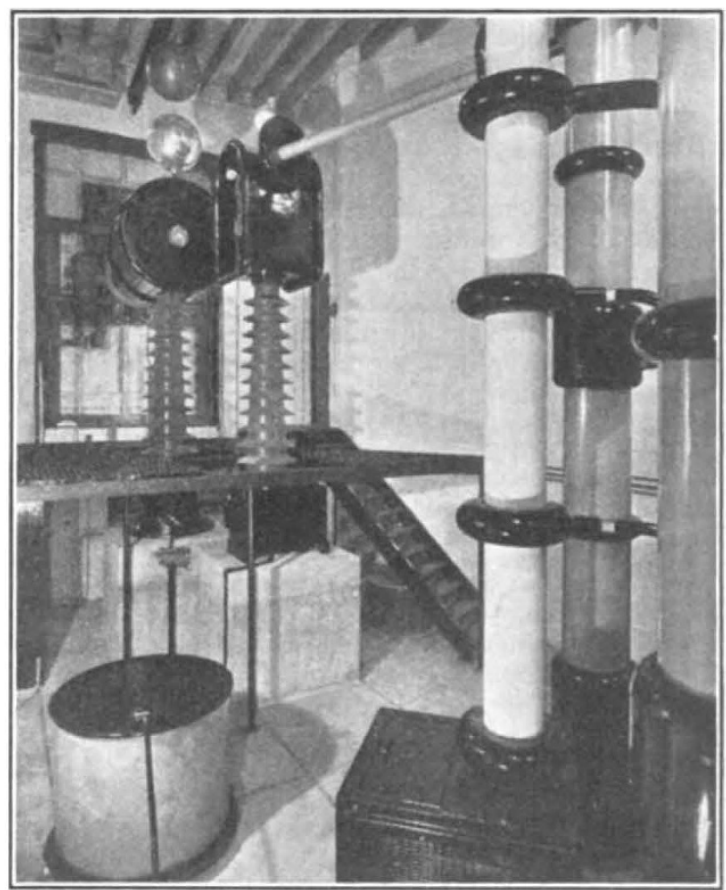

FIG. 2. Generating equipment. Positive end.

logical effects of $\mathbf{X}$-rays generated at high voltages, and the therapeutic application of the results obtained.

\section{The X-RAY Tube}

The X-ray tube is the dominant feature of the Department, and embodies many noteworthy details, both of design and construction. It is thirty feet long, and weighs ten tons. It consists essentially of an inner continuously-evacuated steel tube containing the filament and target. This tube is supported at each end by a porcelain insulator, and extends horizontally from one generator room to the other across the treatment room (Fig. 1). The portion within the treatment room, that is, the central twelve feet, is surrounded by a protective sheath, consisting of a six-inch layer of 'close-packed' lead shot, enclosed between two coaxial steel cylinders. An aperture in this sheath allows the transmission of the X-ray beam. The protective sheath, in its turn, is surrounded by a steel cylinder, which carries the filters, diaphragms, and applicators for defining the X-ray beam. The protective sheath and applicator cylinder can be rotated independently of each other, by means of 
electric motors. In this way it is possible to direct the beam of X-rays at will, either through the applicator towards the patient, or into an absorbing lead saddle, six inches thick, suspended immediately above the tube. Thus, the portion of the X-ray tube within the treatment room is both shock-proof and ray-proof.

As the X-ray tube is fixed, the floor of the treatment room has been made movable, so that the position of the patient relative to the tube may be adjusted as desired.

\section{The Generators}

The generating equipment comprises two generators, one designed to give a positive potential of 600,000 volts, and the other a negative potential of the same value (Fig. 2). The current for each generator is fed from the 400 volt A.c. mains into a transformer from which a current at 150,000 volts can be drawn. By means of a modified Greinacher circuit, embodying columns of continuously-evacuated thermionic valves and oil-immersed condensers, a rectified current at a constant potential of 600,000 volts may be obtained from each generator. Thus by using both generators, a constant potential of more than one million volts may be applied to the $\mathrm{X}$-ray tube. At this voltage, the tube is designed to carry a current of five milliamperes.

The $\mathrm{X}$-ray tube and its generating equipment is the culmination of the remarkable series of $\mathrm{X}$-ray installations designed and manufactured during the past few years by the Metropolitan Vickers Electrical Co., Ltd., of Trafford Park, Manchester. The com. pany is to be congratulated on its fine achievement.

The Treasurer and Governors of St. Bartholomew's Hospital, also, should be congratulated on the vision and energy they have displayed in their endeavour to further the conquest of a dread disease. We wish the new department all success in its work.

\section{Illumination Research at the Science Museum}

$\mathrm{T}^{\mathrm{H}}$

HE special Exhibition on Electric Illumination being held at the Science Museum (see Nature of December 19, p. 1046) contains a number of research exhibits of considerable interest.

One item from which valuable results may be obtained has been contributed by the National Physical Laboratory and has been designed under the supervision of Dr. J. W. T. Walsh. Two light sources, one a tungsten filament lamp and the other equivalent to the mercury discharge lamp, may be adjusted by the observer until equal brightness appears to be obtained by means of a photometer head. When this has been done, the observer records his observation automatically on a roll of paper, thereby contributing towards the accumulation of mass statistics on popular conceptions of heterochromatic photometry. Practically all observations on this subject have been done hitherto by trained observers. It will be interesting to check whether the untrained observer, some 250,000 of whom will probably visit the exhibition, has substantially the same outlook on the question of equal brightness of differently coloured light sources. A rough check with a small number of completely untrained observers at the National Physical Laboratory revealed considerable disparities compared even with the observations of the less-experienced trained observers. The value of a check test to reveal the disparity range in the visual experiences of the general public may be considerable.

Another experimental device with the object of obtaining mass statistics has been installed by the E.L.M.A. Lighting Service Bureau. Variations in the foot-candle intensity chosen by members of the public for comfort in reading are recorded by a ticket issuing machine which, in addition to delivering a ticket showing the value chosen by the operator, records statistically the sum of its operations. Although 5 foot-candles is an average value of illumination experienced in living rooms, it has been found as a result of 20,000 observations that 70 foot-candles is much nearer the desired value for comfort. Further statistics will be obtained at the Exhibition.
A number of other items in the Exhibition illustrate contemporary research without contributing towards it. One most interesting exhibit projects the arc from a mercury discharge lamp on to a translucent screen, and by means of a stroboscopic disk shows that while the cathode discharge emanates from a hot spot on the cathode, the anode discharge takes place from the surface of the electrode presenting the shortest discharge path to the arc. If both these discharges were to take place from the same spot, disintegration of the electrodes would ensue and the lamp life would be uneconomically curtailed. This device, which has been used extensively by research workers to obtain a proper understanding of the processes involved in sustaining the arc discharge in a hot cathode discharge lamp, is now demonstrated to the public.

The phenomenon of luminescence, discovered by Crookes in 1879 and now applied to electric discharge lamps, is demonstrated by a number of cabinets in which only invisible ultra-violet radiation is allowed to fall on luminescent specimens. The first cabinet shows naturally luminescent minerals. The second shows stages in the preparation of a synthetic luminescent material. Pure zinc sulphide is not luminescent, and does not become so with the addition of an impurity. When, however, the mixture is fired, the resultant product is strongly luminescent. Two further cabinets show the response of some materials to long-wave ultra-violet radiation and others to short-wave ultra-violet, and the fact that a material responding to the one may be unresponsive to the other. A fifth cabinet shows the response of the rhodamines which, strangely enough, respond only in the pure form and then only when in either solid or liquid solution.

The water-cooled high-pressure hot cathode mercury discharge lamp is an example of what is at present a research exhibit, but may before long have important practical applications. The tube is of quartz surrounded by a condenser, and from examination of the spectrum of the discharge it is estimated that a temperature of about $8,000^{\circ}$ C.- approximately that 